6 Mercier J-C, Beaufils F, Hartman J-F, et al. Hemodynamic patterns of meningococcal shock in children. Crit Care Med 1988;16:27-33.

7 Hodgetts TJ, Brett A, Castle N. The early management of meningococcal disease. $\mathcal{F}$ Accid Emerg Med 1998;15:72-6.

8 Advanced Life Support Group. Shock. Advanced padiatric life support. 1st Ed. London: BMJ Publishing Group, 1993.

9 Sinclair JF, Skeoch CH, Hallworth D. Prognosis of meningococcal shock. Lancet $1987 ;$ ii: 38 .

10 Heyderman RS, Klein N, Levin M. Pathophysiology and management of meningococcal speticaemia. In: David TJ, ed. Recent advances in paediatrics. No 11. London: Church ill Livingstone, 1993.

11 Baraff LJ. Capillary refill-is it a useful clinical sign? Pediatrics 1993;92:723-4.
12 Schriger DL, Baraff LJ. Capillary refill-is it a useful predictor of hypovolaemic state? Ann Emerg Med 1991;20: 601-5.

13 Gorelick MH, Shaw KN, Murphy KO, et al. Effect of fever on capillary refill time. Pediatr Emerg Care 1997;13:305-7.

14 Britto J, Nadel S, Habibi P, et al. Gastrointestinal perforation complicating meningococcal disease. Pediatr Infect Dis ₹ 1995;14:393-4.

15 Buckmaster ND, Boyce N. Two unusual presentations of Neisseria meningitidis infection. Med 7 Aust 1993;158:286.

16 Buist MD, Power RG, Keeley SR, et al. Severe meningococcal septicaemia associated with splenic rupture. Med $\mathcal{F}$ Aust 1991;155:713.

17 Grewal RP. Atypical presentation of a patient with meningococcaemia. F Infect 1993;27:344-5.

\title{
Hyponatraemic convulsion secondary to desmopressin treatment for primary enuresis
}

\author{
D C Apakama, A Bleetman
}

\begin{abstract}
The case of a 6 year old child who presented with convulsions and coma after unsupervised self administration of intranasal desmopressin (DDAVP) for nocturnal enuresis is presented. Children with enuresis can be embarrassed by their condition and may believe that multiple doses of their nasal spray may bring about a rapid resolution.

Water intoxication is an uncommon but serious adverse effect of treatment with intranasal DDAVP. These patients may present with seizure, mental state changes, or both.

Basic management consists of stopping the drug, fluid restriction, and suppressive treatment for seizures. Recovery is usually rapid and complete.

Administration of the nasal spray in children should be supervised by parents to prevent highly motivated children from accidental overdose. The risks of high fluid intake need to be carefully explained to both parents and children.

( $($ Accid Emerg Med 1999;16:229-230)
\end{abstract}

Keywords: desmopressin; enuresis; water intoxication; hyponatraemia

Desmopressin (DDAVP) is a synthetic analogue of the neurohypophyseal nonapeptide arginine vasopressin. It has greater antidiuretic potency, a reduced pressor activity, and a greater half life and duration of action than the natural hormone vasopressin. ${ }^{1}$ DDAVP is administered intravenously to treat central diabetes insipidus, haemophilia $\mathrm{A}$, and von Willebrand's disease.

Intranasal administration has become popular in the treatment of primary nocturnal enuresis. ${ }^{2}$ The intranasal dose is approximately 10 times greater than the intravenous dose. DDAVP acts on the distal and collecting tubules of the nephron, via the V2 receptors by a cyclic AMP mediated mechanism, to increase their permeability to water and solutes.

A literature search has identified 20 reports of patients in whom intranasal DDAVP was associated with hyponatraemia. All of these patients experienced seizures, altered mental status, or both. ${ }^{2-4}$

\section{Case report}

A 6 year old boy was brought to the accident and emergency department by ambulance after collapsing at school. He had suddenly become drowsy and was witnessed to have a generalised seizure. His parents denied any significant previous medical conditions. The child was reported to have had some behavioural problems. He had been prescribed intranasal DDAVP a week before attendance for control of nocturnal enuresis ( $10 \mu$ daily).

On arrival, he was irritable and had a Glasgow coma score of 9 with dilated and sluggishly reactive pupils. He had a respiratory rate of 16 breaths/min, an axillary temperature of $35^{\circ} \mathrm{C}$, a pulse of 68 beats $/ \mathrm{min}$, and a blood pressure of $104 / 65 \mathrm{~mm} \mathrm{Hg}$. Blood glucose was $8.1 \mathrm{mmol} / \mathrm{l}$. There were no meningeal or focal neurological signs.

While in the department, he had two episodes of jerky uncoordinated movements of the upper limbs which mimicked seizures. Both episodes responded to intravenous diazepam. He was vomiting continuously and had a fluctuating level of consciousness. Blood samples were taken at cannulation and sent for biochemistry and haematology. A non-contrast computed tomogram of the brain was normal.

His blood results were received after the computed tomography. His plasma sodium concentration was $119 \mathrm{mmol} / \mathrm{l}$, potassium $3.5 \mathrm{mmol} / \mathrm{l}$, urea $1.2 \mathrm{mmol} / \mathrm{l}$, and creatinine $52 \mathrm{mmol} / \mathrm{l}$.

On further questioning his parents revealed that the child was highly motivated to resolve his enuresis and had self administered the DDAVP without their supervision. His parents considered it likely that the child might have 
over administered his spray in his enthusiasm to cure his enuresis.

The child was admitted to the paediatric ward where management consisted of discontinuing the drug, fluid restriction, and observation. The day after admission his serum sodium was $131 \mathrm{mmol} / \mathrm{l}$. He made a full neurological recovery and was discharged.

\section{Discussion}

Treatment with DDAVP nasal spray has improved the quality of life of thousands of patients with nocturnal enuresis since its introduction in $1989 .{ }^{3}$ It is well tolerated by most patients. Common local side effects include irritation of the nasal mucosa, rhinitis, and epistaxis. Systemic adverse effects include headache, dizziness, flushing, raised blood pressure, and abdominal pains. ${ }^{2}$ Water intoxication and hyponatraemia are life threatening complications which may occur after accidental overdose or excess fluid intake. DDAVP should be given with care to patients with heart failure, or other conditions which might be aggravated by water retention. The recommended fluid intake during treatment is $30 \mathrm{ml}$ per kg body weight during the four hour period before a dose of DDAVP and for 12 hours afterwards. $^{3}$

The manufacturer recommends monitoring electrolyte concentrations at least once during intranasal DDAVP treatment if its use extends beyond one week.

In the case reported here convulsions developed more than 18 hours after the last dose. This corresponds to the pharmacokinetic properties of DDAVP. The antidiuretic effect of DDAVP becomes effective at 6-26 hours after intranasal application and lasts for approximately 10 hours (plasma half life is $2.2-4.4$ hours). ${ }^{5}$
Basic management consists of stopping the drug, fluid restriction, and suppressive treatment for seizures as necessary. Recovery is usually quick, uncomplicated, and complete.

Robson et al reported seizures and altered levels of consciousness in patients taking conventional dosages of DDAVP. ${ }^{3}$ This can occur in patients with cystic fibrosis or nasal polyps who have an abnormal nasal mucosa. ${ }^{6}$

Drug interaction has not been substantiated, but neurologically active drugs such as methylphenidate and imipramine are thought to potentate the action of DDAVP. ${ }^{7}$

Early symptoms of hyponatraemia are often non-specific and innocuous. They can be easily overlooked or mistaken for a viral illness. ${ }^{2}$ Clear explanation of the hazards of DDAVP treatment to the patient and carers is essential. Children should be supervised when self administering DDAVP nasal spray.

There is not always a clear explanation for the hyponatraemia induced by the use of DDAVP. Further research is required in this area. $^{8}$

\footnotetext{
1 Richardson DW, Robinson AG. A review of desmopressin. Ann Intern Med 1985;103:228.

2 Williford SL, Bernstein SA. Intranasal desmopressininduced hyponatraemia. Pharmacotherapy 1996;16:66-74. 3 Robson WL, Norggard JP, Leung AK. Hyponatremia in patients with nocturnal enuresis treated with DDAVP. Eur f Pediatr 1996;155:959-62.

4 Schwab M, Ruder H. Hyponatremia and cerebral convulsion due to DDAVP administration in patients with enuresis nocturna or urine concentrating testing. Eur $\mathcal{f}$ Pediatr 1997;156:668.

5 Schwab M, Wenzel D, Ruder H. Hyponatremia and cerebral convulsion due to short term DDAVP therapy for control of enuresis nocturna. Eur $\mathcal{F}$ Pediatr 1996;155:46-8.

6 Simmons EJ, Mahoney MJ, Littlewood JM. Convulsions and complications after intranasal desmopressin in cystic fibrosis. BMF 1988;297:1614.

7 Hamed M, Mitchell H, Clow DJ. Hyponatraemic convulsion associated with desmopressin and imipramine treatment. $B M \Im$ 1993;306:1169.

8 Donaghue MB, Latimer ME, Pillsbury L, et al. Hyponatremic seizure in a child using desmopressin for nocturnal enuresis. Arch Pediatr Adolesc Med 1998;152: 290-2.
}

Poole Hospital, Dorset G L A Cumberbatch T J Hampton

Correspondence to: Dr Gary Cumberbatch, Consultant in Accident and Emergency, Poole General Hospital, Longfleet Road, Poole, Dorset BH15 2JB.

Accepted 15 December 1998

\section{Hyperkalaemic paralysis - a bizarre presentation of renal failure}

Gary L A Cumberbatch, Timothy J Hampton

\begin{abstract}
Paralysis due to hyperkalaemia is rare and the diagnosis may be overlooked in the first instance. However it is rapidly reversible and so long as electrocardiography and serum potassium measurement are urgently done in all patients presenting with paralysis, it will not be missed. A case of hyperkalaemic paralysis is described and a review of the emergency management discussed.

(F Accid Emerg Med 1999;16:230-232)
\end{abstract}

Keywords: hyperkalaemia; paralysis; renal failure

\section{Case report}

A 53 year old woman presented to the accident and emergency department with a six hour history of dyspnoea and a 24 hour history of ascending weakness of her limbs. She had no past medical history of note and was on no medication. There had been no symptoms of a preceding viral illness.

On examination she was fully conscious, very pale, and unable to speak. Her respiratory rate was 28 breaths/min though shallow, pulse rate 60 beats $/ \mathrm{min}$, blood pressure $150 / 80 \mathrm{~mm}$ $\mathrm{Hg}$, and she was apyrexial. She had flaccid paralysis of all limbs and no deep tendon 